\title{
Entre o direito, o dever e o risco: olhares de gênero sobre amamentação
}

\begin{abstract}
Resumo
Há mais de um século, a amamentação vem sendo tratada, no Brasil, como uma questão feminina de interesse social e passível de intervenção pelo Estado. Tal realidade não é exclusividade brasileira. Em 1990, 30 países assinaram a Declaração de Innocenti (OMS/Unicef), carta de intenções na qual se comprometiam a estimular a conscientização das mulheres sobre a prática por meio da formulação de políticas nacionais de aleitamento materno e de outras estratégias. Na Europa, Estados Unidos e Canadá, a discussão teórica sobre os dilemas contemporâneos sobre alimentação infantil tem demonstrado bastante fôlego e pode ser traduzida no debate breast versus bottle feeding. No Brasil, embora os discursos oficiais sobre aleitamento materno continuem a atrelar o cuidado com o bebê à amamentação, reforçando a ideia da mãe como responsável insubstituível por essa esfera da vida familiar e social, a discussão carece de maior aprofundamento, sobretudo numa perspectiva de gênero. Este paper problematiza, portanto, o que há de socialmente construído nessas "leis naturais". O corpus analisado reuniu artigos publicados a partir de 2000 em fontes diversas (Scielo, Wiley Online Library, International Breastfeeding Journal, entre outras) e revelou interessantes apropriações da amamentação: como direito que se realiza por meio da retomada do controle da mulher sobre seu corpo; dever moral da mulher para com a nação; e elemento de responsabilização total da mãe pela saúde dos filhos, indicando uma visão predominantemente crítica em relação aos discursos hegemônicos acerca do tema. Acreditamos na importância da contribuição teórica elencada neste trabalho e em sua possível apropriação por pesquisadoras(es) brasileiras(os) envolvidas(os) no debate.
\end{abstract}

Palavras-chave: Amamentação. Maternidade. Família. Estudos de Gênero. Discursos Oficiais.

\section{Para citar este artigo:}

KALIL, Irene Rocha; COSTA, Maria Conceição da. Entre o direito, o dever e o risco: olhares de gênero sobre amamentação. Revista PerCursos. Florianópolis, v. 14, n.27, jul./dez. 2013. p. 07 - 32.

DOI: 10.5965/1984724614272013007

http: //dx.doi.org/10.5965/1984724614272013007

Doutoranda no Programa de PósGraduação em Informação e Comunicação em Saúde da Fundação Oswaldo Cruz - Fiocruz irenekalil@gmail.com

Maria Conceição da Costa

Doutorado em Ciência Política e livre docente pela UNICAMP mariacon.2005@gmail.com 


\title{
Right, duty or risk: views of gender on breastfeeding
}

\begin{abstract}
For over a century, breastfeeding has been treated in Brazil as a social issue, subject to intervention by the State. This reality is not exclusively Brazilian. In 1990, 30 countries signed the Innocenti Declaration (WHO/Unicef), letter of intent in which they committed themselves to raising awareness of women about the practice through the development of national breastfeeding policies and other strategies. In Europe, United States and Canada, the theoretical discussion of contemporary dilemmas about infant feeding has shown quite breathtaking and can be translated in the debate breast versus bottle feeding. In Brazil, although official discourses about breastfeeding continue to tow the care of the baby for breastfeeding, reinforcing the idea of the mother as irreplaceable responsible for this sphere of family and social life, the discussion needs further strengthening, especially from a gender perspective that problematizes what is socially constructed in these "natural laws ". The analyzed corpus gathered articles published since 2000 on various sources (Scielo, Wiley Online Library, International Breastfeeding Journal, among others) and revealed interesting appropriation of breastfeeding, such as: right that is realized through the resumption of control of women over their own bodies; women's moral duty to the nation; and total accountability element mother for the health of children, indicating a predominantly critical view of the hegemonic discourse on the subject. We believe the importance of theoretical contribution gathered in this study and its possible appropriation by Brazilian researchers which are involved in this debate.
\end{abstract}

Keywords: Breastfeeding. Motherhood. Family. Gender Studies. Official Discourses. 


\section{Situando a problemática}

Para Perrot (2003), as mulheres têm sido, ao longo do tempo, seres esquecidos e silenciados na História, sobretudo no que se refere ao seu corpo, sempre associado à função da procriação. A autora afirma que, embora onipresente nas palavras de poetas, médicos e políticos, o corpo feminino é sempre objeto do olhar, do desejo e do discurso, nunca sujeito. "Fala-se dele. Mas ele se cala. As mulheres não falam, não devem falar dele. O pudor que encobre seus membros ou lhes cerra os lábios é a própria marca da feminilidade" (PERROT, 2003, p. 13).

No entanto, as mulheres têm, cada vez mais, tomado para si o direito da palavra. É possível perceber que, desde meados do século $X X$, suas perspectivas de análise tornaram-se mais frequentes na reflexão sobre temáticas diversas que se mostram importantes na realidade contemporânea, dentre elas, questões relacionados à maternidade, inclusive no âmbito da saúde, constantemente marcado pela divisão binária do mundo baseada em diferenças biológicas.

Um exemplo pode ser visto no livro que a filósofa e feminista francesa Elisabeth Badinter publicou, em 1980, sob o título de L'amour en plus, lançado no Brasil alguns anos depois (Um amor conquistado: o mito do amor materno, 1985). A obra descontrói a ideia do amor materno como instinto ou tendência feminina inata, apontando-o como uma construção social, que varia - e variou - de acordo com as diferentes épocas e seus costumes. Entretanto, no prefácio à edição de bolso, Badinter declarou-se surpresa com as reações apaixonadas que o livro provocou, demonstrando como a maternidade ainda é, em nossos dias, um tema da ordem do sagrado. "Continua difícil questionar o amor materno, e a mãe permanece, em nosso inconsciente coletivo, identificada a Maria, símbolo do indefectível amor oblativo" (BADINTER, 1985, p. 9), constatou a autora.

Na profunda reflexão histórica sobre modelos de maternidade que Badinter (1985) propõe, ela destaca a crescente valorização do aleitamento materno como pilar da construção moderna da maternidade, que se fortaleceu, especialmente, com o surgimento de La Leche League (LLL), organização civil norte-americana empenhada na 
promoção do aleitamento materno em diversos países. A autora afirma que, sobretudo nos últimos vinte anos, temos presenciado mundialmente uma verdadeira "batalha do leite", protagonizada nos Estados Unidos e em vários países pela LLL. Na ideologia pregada por essa instituição, a mãe que amamenta carrega um papel social fundamental, que é o de garantir aos filhos um desenvolvimento harmonioso, vantajoso não apenas para eles, mas também para a sociedade como um todo.

$\mathrm{Na}$ Europa, Estados Unidos e Canadá, a discussão teórica sobre os dilemas contemporâneos relacionados à alimentação infantil vem demonstrando fôlego crescente e é comumente traduzida no acalorado debate breast $X$ bottle feeding. No Brasil, esse terreno ainda precisa ser melhor explorado. Embora já existam diversos estudos que enfocam as percepções maternas acerca da amamentação e suas divergências em relação ao discurso oficial, a perspectiva de análise, geralmente vinculada à atenção à saúde, é a de conhecer essas diferenças para melhor atuar visando a uma maior adoção da prática pelas mulheres. Uma vez que, na perspectiva da divisão do mundo em papéis sexuais, a maternidade continua sendo uma das funções elementares atribuídas à mulher, buscamos, neste paper, destacar os diferentes olhares dos estudos de gênero sobre a amamentação por acreditamos ser esta uma apropriação necessária e mesmo fundamental para a reflexão sobre a temática nos dias atuais.

O termo "gênero" começou a ser utilizado no âmbito acadêmico mundial, desde a década de 1970, como ferramenta conceitual de análise das desigualdades sociais entre homens e mulheres na sociedade (Corrêa, 2011). Tais usos foram influenciados, de acordo com Corrêa (2011), pela contribuição da antropologia social, que, por meio de diversas antropólogas feministas que fizeram um retorno crítico aos autores clássicos da disciplina, estabeleceu novos parâmetros para analisar as lógicas de sexo e gênero e promoveu revisões à utilização de categorias ocidentais de análise para "pensar a articulação entre gênero e população ou gênero e demografia" (CORRÊA, 2011, p. 341).

Segundo a autora, foi com o chamado "giro linguístico", que ocorreu em função do estabelecimento da categoria de gênero nas análises sociais, que as pensadoras feministas afastaram-se das correntes estruturais e historicistas que antes norteavam seus trabalhos, voltando o foco para os discursos, vistos agora como "fontes de 
normatização e hierarquia" (CORRÊA, 2011, p. 341). Também surgiu, naquele momento, uma maior preocupação com a "variabilidade cultural dos significados de gênero das normas e práticas sociais" (CORRÊA, 2011, p. 341).

O conceito de gênero que norteia este trabalho é o de categoria analítica, fruto de uma construção social, que questiona a naturalização da dualidade sexual como constitutiva da essência fixa e imutável do ser, reconhecendo que a ênfase nas diferenças anatômicas foram essencializadas em contextos históricos e culturais específicos. Como apontou Meyer (2004), quando um grupo de estudiosas anglo-saxãs começou a utilizar o termo gender, a despeito das suas diversas apropriações, o conceito de gênero pretendia:

[...] Colocar em xeque a equação - que resultava em diferenças reconhecidas como sendo inatas e essenciais - na qual se articulava um determinado modo de ser a um sexo anatômico que the seria 'naturalmente' correspondente, para argumentar que diferenças e desigualdades entre mulheres e homens eram social e culturalmente construídas e não biologicamente determinadas. (MEYER, 2004, p.14)

É, portanto, pautados nesse referencial teórico que entendemos a necessidade de refletir sobre a perpetuação, em nossas sociedades, da cristalização e naturalização de papéis sexuais na vida cotidiana, que se reproduzem fortemente por meio de discursos seculares do campo da saúde. Meyer (2004) destacou que, sobretudo na área da saúde, não se trata de negar a materialidade do corpo, mas de redefinir o foco das análises - "do 'corpo em si' para os discursos, processos e relações que possibilitam que sua biologia passe a funcionar como causa e explicação de diferenciações e posicionamentos sociais" (MEYER, 2004, p. 16).

Especificamente no que se refere ao âmbito das políticas públicas de aleitamento materno, percebemos que os discursos oficiais continuam a atrelar a maternagem ou cuidado com o bebê à amamentação, reforçando, consequentemente, a ideia da mãe como responsável insubstituível por essa esfera da vida familiar e social. Nesse caso, é a perspectiva de gênero que salienta o que há de socialmente construído nessas "leis naturais", permitindo-nos problematizar o imaginário comumente aceito de uma divisão sexual do trabalho com bases puramente biológicas.

A seleção que trazemos é composta por artigos publicados a partir de 2000 e 
buscados, de forma não sistemática, utilizando os descritores amamentação or aleitamento materno and gênero or feminismo (breastfeeding and gender or feminism) em diversas fontes (Scielo, Google Acadêmico, Wiley Online Library, International Breastfeeding Journal, entre outras). Também utilizamos, como interlocutores, livros de autores que se debruçaram sobre o assunto da amamentação e dos modelos de maternidade contemporâneos, acreditando enriquecer a reflexão proposta. Selecionamos alguns posicionamentos teóricos recentes de pesquisadoras e pesquisadores a respeito do tema numa perspectiva de gênero, embora conscientes de que há, certamente, um vasto campo de abordagens do tema que não pôde ser aqui esgotado.

Em razão de um menor número de artigos e livros sobre o assunto publicados por autores brasileiros nesse mesmo período, há, neste trabalho, uma prevalência de pesquisas de origem norte-americana e canadense. Tentamos, na abordagem dessas reflexões, considerar as particularidades de seus contextos e suas diferenças em relação a nossa realidade no que tange a políticas e práticas, apostando na importância de sua contribuição teórica e em sua possível apropriação por pesquisadoras(es) brasileiras(os) envolvidas(os) no debate.

\section{Amamentação como direito e controle sobre o próprio corpo}

Em editorial para o Breastfeeding International Journal, Labbok, Smith (2008) e Taylor (2012) apresentaram as principais discussões realizadas durante o Third Annual Breastfeeding and Feminism Symposium, ocorrido na Carolina do Norte, Estados Unidos, em 2007. O evento surgiu com o objetivo de reposicionar a amamentação como uma parte importante das vidas e dos direitos reprodutivos das mulheres. De acordo com as autoras, a cada ano, são feitos esforços no sentido de aumentar a presença do aleitamento materno como tema dentre os grupos de direitos das mulheres e comunidades de estudos feministas, bem como o reconhecimento, entre defensores da amamentação, de que o aleitamento materno poderia obter maior apoio político e social se estivesse associado aos que estão preocupados com questões como saúde 
reprodutiva, direitos, justiça, avanço econômico das mulheres, eliminação de todos os tipos de inequidades: sociais, econômicas e de saúde. Trata-se, então, de uma tentativa de aproximar, cada vez mais, o discurso pró-amamentação de uma perspectiva de gênero, privilegiando a prática sob a ótica dos direitos femininos.

Essa perspectiva da amamentação como um direito da mulher e um processo de empoderamento sobre seu próprio corpo é novamente apontada por Smith (2008) ao entrevistar mulheres participantes de eventos em prol do aleitamento materno, da valorização da maternidade e dos direitos reprodutivos da mulher. A autora destaca que a alimentação infantil ocorre em um contexto de desigualdades de gênero, que inclui falta de suporte familiar, trabalhista e comunitário para a amamentação; sexualização dos seios femininos e, por outro lado, estigmatização do seio maternal, que limita as possibilidades de a mulher amamentar em público'; além da falta de informação para a mulher sobre os benefícios do aleitamento materno, entre outros obstáculos.

Tudo isso, segundo ela, concorre para criar "an environment that medicalizes and commercializes infant feeding while undermining women's capacity to breastfeed and alienating them from their maternal breast"'2(SMITH, 2008, p. 1).

Smith (2008) toma o conceito de "repossession" (que traduzimos como reapropriação) para explicar como essas mulheres vêm adotando uma estratégia de se reconectarem à amamentação como uma experiência da qual foram alienadas, inclusive, por meio da teoria e da prática liberais feministas.

Reconhecemos, nesses artigos, uma tentativa de abordagem da amamentação relacionada ao posicionamento das mulheres na sociedade e suas demandas. Ainda que não desvencilhada de sua vinculação com a saúde da criança, são privilegiadas suas ligações com a saúde reprodutiva da mulher, seu empoderamento sobre o próprio corpo, decisões reprodutivas e direito de escolha frente a uma sociedade excessivamente

\footnotetext{
1 Essa "estigmatização" do seio maternal, derivada, segundo Wolf (2008), do excessivo foco sexual que ganharam os seios femininos na sociedade norte-americana, é apontada por alguns autores como fator dificultador da amamentação. A liberdade para amamentar em locais públicos é uma das bandeiras de grupos feministas ligados ao aleitamento materno e aos direitos reprodutivos nos Estados Unidos (SMITH, 2008; WOLF, 2008).

2 “... um ambiente que medicaliza e comercializa a alimentação infantil enquanto mina a capacidade das mulheres para amamentar e as aliena do seio maternal”. (TN)
} 
medicalizada e às pressões das indústrias alimentícias voltadas ao segmento infantil, que se apoiam no discurso da "escolha" para induzirem as mães a uma "escolha direcionada" por outros interesses, sobretudo econômicos, em uma sociedade que não proporciona a estrutura necessária para que a mulher possa escolher amamentar (HAUSMAN, 2008).

Tal abordagem pode ser identificada com uma segunda onda feminista caracterizada por Badinter (2011) como uma espécie de naturalismo ou maternidade ecológica, iniciada, na Europa e América do Norte, na virada da década de 70 para 80, contrapondo-se à bandeira mais culturalista das primeiras correntes do feminismo, que apostavam na igualdade entre os sexos por meio do destaque às semelhanças entre homens e mulheres. Por considerar "a maternidade a experiência crucial da feminilidade a partir da qual se pode construir um mundo mais humano e mais justo" (BADINTER, 2011, p. 71), esse movimento traduz um processo de valorização das diferenças biológicas entre os sexos por meio do reconhecimento do caráter natural da maternidade e da amamentação e de sua apropriação como a realização de um desejo e uma forma de afirmação da feminilidade.

A maternidade ecológica parece ter suas raízes na atuação de La Leche League (LLL). Criada em 1956, por iniciativa de um grupo de mães da classe média de Chicago, militantes no tradicionalista Christian Family Movement (Movimento da Família Cristã), a LLL surgiu com o propósito de "ajudar 'de mãe para mãe' todas as que desejam amamentar sem ousar fazê-lo por medo das dificuldades" (BADINTER, 2011, p. 87).

Rapidamente, a ideologia pregada pela LLL espalhou-se pelo mundo. O famoso livro The womanly art of breastfeeding (A arte feminina da amamentação), publicado pela organização em 1958, contabilizava, em 1990, mais de 2 milhões de exemplares vendidos. De acordo com Badinter, a obra baseava sua argumentação relativa à maternidade e à amamentação em dois princípios claramente formulados: "o primeiro diz que a boa mãe põe 'naturalmente' as necessidades do filho acima de tudo. O segundo, que as necessidades do filho são estabelecidas pela 'natureza', e que são progressivamente cada vez mais conhecidas" (BADINTER, 2011, p.88).

Hoje, La Leche League International está presente em mais de 60 países. Sua filosofia, traduzida em dez preceitos básicos, já faz parte do imaginário científico e leigo 
da grande maioria das sociedades contemporâneas. A naturalidade do ato de amamentar e sua centralidade na vivência do cuidado com o bebê, a importância do elo emocional entre mãe e filho proporcionado pela amamentação, a superioridade do leite materno em relação a qualquer outro alimento dirigido a lactentes, o protagonismo da criança no processo de amamentação e desmame, com a priorização de suas necessidades em detrimento das necessidades da mãe, entre outras afirmações são aceitas e propagadas pelas principais organizações internacionais que atuam em prol do aleitamento materno e compõem o discurso reproduzido, no âmbito das políticas públicas, por grande parte das nações ocidentais.

\section{Amamentação, responsabilidade total da mãe pela saúde dos filhos e a medida da boa mãe}

O aleitamento materno é hoje considerado, por organizações internacionais como a Save the Children, a estratégia isolada focada na criança mais efetiva no combate à morbimortalidade infantil em todo o mundo. De acordo com estudos recentes, somente a suplementação de ácido fólico, que é feita pela mãe durante a gravidez, traz mais efeitos positivos para a garantia da saúde da criança (O'CONNOR; VAN ESTERIK, 2012). Em razão disso, no entendimento de diversos autores, em variadas realidades nacionais, o Estado e a sociedade têm colocado na mulher e na gestão de seu corpo a responsabilidade pela saúde dos filhos, da família e da própria nação, tornando-a "an important layer of the health-care system"3 (KUKLA, 2006, p. 157).

Nas sociedades economicamente mais prósperas, onde a mortalidade infantil não é mais um grande problema de saúde pública, Badinter (2011) insinua que há outras formas de convencer a mulher a amamentar, tratando do risco da não amamentação para o perfeito desenvolvimento físico, mental e emocional do bebê. O comportamento descrito pela autora, que põe em relação amamentação e a ideia do risco em saúde, é apontado, mais diretamente, quando caracteriza o novo paradigma em vigor na sociedade norte-americana atual: a "total motherhood" (WOLF, 2007) ou "intensive mothering" (HAYS, 1998).

\footnotetext{
${ }^{3}$ [Mães servem] como um importante estrato do sistema de saúde. (TN)
} 
Total motherhood is a moral code in which mothers are exhorted to optimize every dimension of children's lives, beginning with the womb, and its practice is frequently cast as a trade-off between what mothers might like and what babies and children must have. When mothers have wants, such as a sense of bodily, emotional and psychological autonomy, but children have needs, such as an environment in which anything less than optimal is framed as perilous, good mothering is construed as behavior that reduces even minuscule or poorly understood risks to offspring, regardless of potential cost to the mother ${ }^{4}$. (WOLF, 2007, p. 615 , grifo da autora)

Esse novo modelo ou ideologia de maternidade, no qual cabe à mãe proteger o filho de todos os riscos, desde a gestação, instituindo regras para a criação dos filhos a serem seguidas por todas as mães, vem norteando algumas políticas estatais no campo do aleitamento materno. É o caso da campanha televisiva analisada por Wolf (2007), veiculada nos Estados Unidos no período de 2004 a 2006, que comparava os riscos da não amamentação para o bebê aos de uma mulher no terceiro trimestre de gravidez subir em um touro mecânico. A mensagem do spot televisivo não deixava dúvidas quanto à estratégia de convencimento utilizada, alertando as mulheres "that not breast-feeding put babies at risk for a variety of health problems. 'You'd never take risks before your baby is born. Why start after?""5 (WOLF, 2007, p. 595).

Também Knaak (2006) critica a forma como os discursos pró-aleitamento têm sido construídos, utilizando-se do elemento risco quando se trata de caracterizar a não amamentação. Para a autora, existe uma espécie de "seletividade científica" em relação ao assunto, revelada no destaque a estudos que enfatizam os múltiplos benefícios da amamentação e os riscos associados à alimentação com fórmula que podem estar comprometidos por não controlarem as demais variáveis que influenciam a saúde do

\footnotetext{
${ }^{4}$ Maternidade total é um código moral em que as mães são encorajadas a otimizar todas as dimensões da vida das crianças, começando no ventre, e sua prática é frequentemente colocada como uma negociação entre o que as mães possam gostar e que os bebês e as crianças devem ter. Quando as mães têm desejos, tal como uma sensação de autonomia corporal, emocional e psicológica, e as crianças têm necessidades, como um ambiente em que qualquer coisa que seja menos do que ideal é enquadrada como perigosa, a boa maternidade é interpretada como um comportamento que reduz até mesmo os riscos minúsculos ou desconhecidos para a prole, independentemente do custo potencial para a mãe. (TN)

${ }^{5}$ Que não amamentar coloca os bebês em risco para uma variedade de problemas de saúde. 'Você nunca correu riscos antes de seu bebê nascer. Por que começar depois?'. (TN)
} 
bebê, como, por exemplo, a condição socioeconômica da família. Ela argumenta que comunicar a população sobre as estatísticas dos riscos associados à amamentação e à alimentação com fórmula é necessário, mas que isso deve ser feito garantindo uma articulação clara entre essas variáveis e as outras, de modo contextualizado.

It is also important to situate the relative health impacts of infant feeding within a broader context of risk. For example, how significant to overall health is the quality of a child's solid food diet in comparison to their infant diet? What ultimately presents a bigger risk for respiratory infection - exposure to viruses (perhaps through a school-age sibling) or formula feeding? And how significant is a respiratory infection to overall infant health in relation to other health concerns, such as accidents for example? ${ }^{6}$ (KNAAK, 2006, p. 413)

No Brasil, a questão do risco também começa a ganhar espaço na reflexão sobre os discursos contemporâneos relativos à maternidade e a amamentação. Amorim (2008) afirma que, desde o retorno do incentivo ao aleitamento materno, entre o final da década de 1970 e início da de 1980, os discursos caracterizam-se por uma tentativa de convencimento da mulher para a prática da amamentação de forma radical, enfocando, sobretudo, os benefícios do aleitamento materno para a saúde da criança. Na declaração da OMS/Unicef de 1979, a amamentação já era apontada como uma espécie de "salvação para os bebês", uma estratégia de desenvolvimento "ao alcance de todos os países, muito mais próxima e mais econômica do que se podia imaginar" (AMORIM, 2008, p. 592).

Como destaca a autora,

Nesse momento, a valorização da criança, seu crescimento e desenvolvimento adequado e sua proteção contra morbidades que poderiam facilmente levá-la à morte foram o argumento dos discursos em defesa do aleitamento materno. (AMORIM, 2008, p. 595)

\footnotetext{
${ }^{6}$ Também é importante situar os impactos na saúde relativos à alimentação infantil dentro de um contexto mais amplo de risco. Por exemplo, o quão significativo para a saúde geral é a qualidade da dieta sólida de uma criança em relação à sua dieta infantil? O que, em última análise, representa um risco maior para infecção respiratória - a exposição ao vírus (talvez por meio de um irmão em idade escolar) ou a alimentação com fórmula? E quão importante é uma infecção respiratória para a saúde global infantil em relação a outros problemas de saúde, tais como acidentes, por exemplo? (TN)
} 
No mesmo sentido, Scavone (2004) aponta a responsabilidade depositada na mulher pela conservação da vida e pela saúde, que é intensificada durante a gestação e a amamentação, períodos nos quais essa proximidade ou indissociação corporal entre mãe e filho facilita a criação de uma "fantasia de causa e efeito" (SCAVONE, 2004, p. 135). "É como se, da responsabilidade de alimentar, as mulheres passassem a ter, também, a responsabilidade por toda e qualquer doença dos filhos" (SCAVONE, 2004, p. 136), ressalta a autora.

Esse mesmo modelo de definir uma "relação mãe-filho 'normal' e 'natural"” (Meyer, 2004, p. 16) foi caracterizado por Meyer (2004) como uma nova politização da maternidade. Nova não por ser inovadora, mas por se configurar como uma atualização mais complexa de velhos paradigmas educativo-assistenciais que têm como foco as mulheres. A autora enfatiza que, no contexto atual, cabe à mulher que se torna mãe a responsabilidade total de gerar e criar filhos 'equilibrados' e 'saudáveis', “independentemente das condições sociais em que essa mulher vive e dos problemas que ela enfrenta - um projeto que deve começar a ser preparado, em todos os sentidos, desde muito cedo, e que deve pautar sua vida como mulher" (MEYER, 2004, p. 16).

Tais discursos da saúde reforçam a ideia de que, antes mesmo de se tornar mãe, a mulher precisa ter uma vida considerada potencialmente saudável para sua prole - não beber ou fumar, fazer exercícios físicos, construir uma boa condição financeira e escolher bem seu parceiro -, moralizando os comportamentos femininos e distinguindo aqueles considerados aceitáveis dos que deveriam ser vistos como inadequados ou desviantes.

\section{Amamentação e entraves à emancipação feminina}

Autores de diversos campos têm chamado atenção para os limites e possibilidades contemporâneas de conciliação entre a amamentação e a função materna como concebida na atualidade e o investimento da mulher na carreira. Essa relação tem sido analisada, de modo geral, na perspectiva de como o trabalho de meio período seria uma estratégia para auxiliar as mulheres a combinar amamentação e emprego (FEIN; ROE, 1998); ou de como a ampliação da licença maternidade, mudanças no ambiente de trabalho e leis específicas de proteção à mulher que amamenta podem beneficiar os 
índices de amamentação entre mulheres trabalhadoras (BRASILEIRO et al, 2012). Nesses casos, entende-se o trabalho da mulher como um potencial obstáculo ou, ao menos, dificultador da amamentação.

O cumprimento das leis de proteção à amamentação parece ser fundamental em uma sociedade como a brasileira, em que quase $25 \%$ da população economicamente ativa é constituída por mulheres com filhos menores de seis meses de idade. (BRASILEIRO et al, 2012, p. 647)

No entanto, uma aproximação interessante e, em certa medida, inusitada é feita por Rippeyoung e Noonan (2009). Os autores afirmam que o olhar acadêmico sempre está focado na influência negativa do trabalho da mulher para o sucesso da amamentação e que é preciso investigar se o aleitamento materno interfere no trabalho feminino, ou seja, se a relação opera também na direção oposta.

Particularly considering that, temporally, the act of breastfeeding a newborn preceeds a mother's return to work after childbirth, it seems plausible that, compared to a mother who formula feeds her child, a mother who breastfeeds her child may be more likely to leave paid employment, either partially or fully, or be more likely to switch to a "family-friendly" job in order to accommodate breastfeeding (REYNOLDS, 2005). These modifications in work behavior may, in turn, lower the breastfeeding mother's current and future earnings. ${ }^{7}$ (RIPPEYOUNG; NOONAN, 2009, p. 1)

Rippeyoung e Noonan (2009) argumentam que são necessárias mais pesquisas que se debrucem sobre o tema, considerando que muitas mulheres podem reduzir suas jornadas de trabalho, tirar licenças-maternidade mais longas, mudar para um emprego mais compatível com a vida em família ou mesmo largar o trabalho em função da amamentação. Para os autores, tais pesquisas são relevantes para o entendimento teórico das inequidades de gênero existentes tanto no mercado de trabalho quanto nas políticas públicas voltadas para o apoio ao trabalho feminino e às demandas familiares.

\footnotetext{
7 Especialmente considerando que, temporariamente, o ato de amamentar um recém-nascido precede o retorno da mãe ao trabalho após o parto, parece plausível que, em comparação com uma mãe que alimenta seu filho com fórmula, uma mãe que amamenta seu filho pode ser mais propensa a deixar o emprego pago, parcial ou totalmente, ou a mudar para um emprego mais compatível com a vida em família a fim de acomodar a amamentação (REYNOLDS, 2005). Essas modificações no comportamento de trabalho pode, por sua vez, reduzir o salário atual e futuro da mãe que amamenta. (TN)
} 
Historicamente, os padrões sociais sobre amamentação têm se articulado à possibilidade ou não de emancipação feminina do poder patriarcal por meio da sua independência profissional e financeira. Acerca desse assunto, Costa (1999) afirma que "a pressão higiênica em favor da amamentação tinha outros objetivos, além da proteção à vida das crianças. [...] A mulher que não amamentasse isentava-se, automaticamente, de uma ocupação indispensável à redefinição de seu lugar no universo disciplinar" (COSTA, 1999, p. 258).

O mesmo autor ressalta que a restrição da atuação da mulher ao espaço doméstico, evitando assim sua concorrência com o homem no mundo do trabalho, era um dos objetivos disciplinares do aleitamento materno, juntamente com "o uso higiênico do tempo livre da mulher na casa" (COSTA, 1999, p. 258), que evitava que ela se perdesse no ócio e em passatempos considerados moralmente inadequados, e a manutenção da coesão do núcleo familiar, buscando-se, por meio da amamentação, “depositar na mulher a responsabilidade pela unidade da família e dar ao homem maior disponibilidade para outras obrigações sociais" (COSTA, 1999, p. 261-262).

Desde o século XVIII, na Europa, e da virada do século XIX para o século XX, no Brasil, que o controle social sobre o corpo feminino tinha, entre seus objetivos, destinar à mulher a responsabilidade pelo espaço privado, enquanto cabiam ao homem as relações no espaço público. Para as mulheres das classes médias abastadas e da elite, portanto, o aleitamento materno como dever biológico e social impunha dificuldades a sua autonomia e ao possível ingresso no mercado de trabalho, evitando sua concorrência com profissionais do sexo masculino.

Como observou Amorim (2008), esta é uma diferença fundamental entre os discursos a favor da utilização de fórmulas na alimentação de lactentes, difundidos até a década de 1970, e os discursos anteriores e posteriores a eles (tanto no higienismo quanto no retorno do incentivo ao aleitamento materno, a partir do final década de 1970). Enquanto os primeiros tinham como contexto a segunda onda feminista, a difusão da pílula anticoncepcional e a regulamentação do trabalho feminino no país, voltando sua atenção, principalmente, para a liberdade da mulher, os discursos pró-aleitamento 
materno concentravam seu foco na criança e desvalorizavam qualquer obstáculo da mulher, inclusive a trabalhadora, na prática da amamentação.

$\mathrm{Na}$ análise da abordagem do aleitamento materno e artificial em revistas voltadas ao público feminino entre 1960 e 1988, a autora constatou que muitos dos apelos utilizados para a mulher amamentar no final do século XVIII e ao longo do século XIX continuavam os mesmos nas últimas décadas do século XX. Uma reportagem analisada por ela sugere que "o fato de a mãe trabalhar fora, ter que cumprir horários rígidos, enfrentar trânsito ou ônibus superlotados, correr, realizar ou administrar todas as tarefas domésticas não a impedem de amamentar" (AMORIM, 2008, p. 593), ratificando a ideia de que "Só não amamenta quem não quer".

Atualmente, a política pública voltada ao aleitamento materno no Brasil reconhece o trabalho da mulher como uma questão a ser equacionada no sentido de sua adequação às necessidades da amamentação. Exemplos dessa preocupação governamental é a publicação de cartilhas voltadas a mulheres trabalhadoras e empresas para promover a sensibilização para o aleitamento materno no ambiente de trabalho, bem como uma atuação específica do Ministério da Saúde que visa estimular as empresas a criarem "salas de apoio à amamentação", possibilitando a retirada e acondicionamento do leite humano no período em que a mãe estiver longe do bebê, contribuindo para a manutenção da amamentação após o término da licença maternidade.

\section{Amamentação como dever moral e fator gerador de culpa e vergonha}

Mais recentemente, ao tratar das mudanças no discurso hegemônico sobre a maternidade, Badinter (2011) destaca que, ainda que as razões elencadas sejam outras, mantém-se, nos dias atuais, a lógica de transformação dos costumes por meio do poder da culpabilização da mulher. É ela a responsável, ontem e hoje, pela estabilidade familiar e pela prosperidade da sociedade.

No século XVIII, Rousseau, os médicos e os moralistas souberam tocar nesse ponto sensível para convencer as mães a se dedicarem exclusivamente aos filhos, amamentá-los e educá-los. Tratava-se da sobrevivência deles, da felicidade da família, do poder danação. Hoje em 
dia, os argumentos mudaram um pouco. Nas sociedades em que a mortalidade infantil está em seu menor nível, não se apela mais para a sobrevivência das crianças, mas para sua saúde física e psíquica, determinante para o bem-estar do adulto e da harmonia social. Qual a mãe que não sentirá, no mínimo, uma pitada de culpa se não se conformar às leis da natureza? (BADINTER, 2011, p. 79)

Essa culpa que a mulher que não amamenta - ou não amamenta nos parâmetros preconizados pelas organizações internacionais - sente é um processo que deriva, segundo Taylor e Wallace (2012), das duas apropriações de amamentação apontadas anteriormente. Em primeiro lugar, deve-se a uma não correspondência da mulher aos padrões da maternidade total (WOLF, 2007). Sua atitude de não amamentar ou de interromper o aleitamento por limitações físicas ou necessidades pessoais faz com que ela se sinta culpada ou, segundo Taylor e Wallace (2012), mais do que culpada, com vergonha diante do julgamento moral da sociedade, por colocar em risco a saúde do seu bebê.

Em segundo lugar, sentindo-se incapaz de atender ao ideal de maternidade em voga, a mãe que não amamenta se sente também menos mulher. Isto, segundo as autoras, fundamenta-se na proposição de muitos defensores do aleitamento materno de uma relação entre a amamentação e a feminilidade ou entre a amamentação e a própria “natureza feminina”. Para elas, a mensagem dos discursos pró-aleitamento "that all women can breastfeed implies that any woman who cannot or does not is shameful, an incomplete woman"8 (TAYLOR; WALLACE, 2012, p. 85).

As autoras identificam, ainda, um fato interessante: as mulheres que amamentam também manifestam um sentimento de vergonha, desta vez associada ao ato de amamentar em público seus bebês. Nos Estados Unidos, diversos estudos - tanto com sujeitos de pesquisa quanto artigos de cunho feminista e de defesa do aleitamento materno - enfocam as dificuldades das mulheres para amamentar em locais públicos em razão do desconforto que isso geraria para uma grande parcela da população. Tal desconforto, segundo Wolf (2008), estaria ligado a um foco no propósito sexual dos seios femininos pela sociedade norte-americana. Embora seja possível supor que, também no

\footnotetext{
${ }^{8} \mathrm{~A}$ mensagem de que todas as mulheres podem amamentar implica que qualquer mulher que não consiga ou não o faça seja vergonhosa, uma mulher incompleta. (TN)
} 
Brasil, algumas mulheres que amamentam se sintam desconfortáveis com o ato de amamentar em público, sobretudo em determinadas classes sociais, não encontramos estudos empíricos que tratem, especificamente, desse tema.

Knaak (2006) é outra autora que destaca o sentimento de inadequação que os discursos pró-aleitamento materno geram em muitas mulheres. A pesquisadora critica a forma como são construídos esses discursos, que, de acordo com ela, estão mais próximos da publicidade e da persuasão do que da educação. Além de serem baseados em um processo que a autora denomina de "inapropriada 'seletividade científica"” (KNAAK, 2006, p. 413), refletindo uma representação parcial da literatura científica relativa ao tema, esses discursos correm o risco de difundir mitos de uma maternidade idealizada, que não encontra reflexo na variabilidade de experiências vividas pelas mulheres no processo da alimentação infantil.

No Brasil, Meyer (2004) afirma que a leitura dos discursos proferidos nos materiais educativos governamentais sobre aleitamento materno evidencia como "se tornaram complexas, multivariadas e quase que irrefutáveis as vantagens dessa prática que é apresentada como sendo a mais importante prova do amor e da competência maternas" (MEYER, 2004, p. 17). Nesse sentido, a autora argumenta que a prática do aleitamento materno como vem sendo recomendada pelos organismos internacionais e nacionais (exclusivo nos seis primeiros meses de vida do bebê no regime de livre demanda, ou seja, sempre que o bebê quiser mamar) pode ser vista como um exemplo do que chamou de um processo de politização da maternidade (MEYER, 2004, 2003).

Chama atenção, nesse contexto, tanto a centralidade que a prática do aleitamento e, por extensão, o cuidado com o bebê deve assumir na vida da mulher-mãe quanto o processo de equalização de tais ensinamentos, que devem interpelar, indistintamente, todas as mulheres, independentemente de sua inserção social e cultural. (MEYER, 2003, p. 46)

Ou seja, todas as mulheres são capazes de amamentar, salvo em raras exceções nas quais, e somente nelas, é aceita a não amamentação temporária ou definitiva, como no caso do uso de determinados medicamentos e de mulheres portadoras do vírus HIV/Aids (MEYER, 2003, p. 48). A autora identifica que esses discursos produzem o 
aleitamento materno como um imperativo, reservando pouco espaço para "consideração de condições sociais, culturais ou psicológicas que possam impedir ou dificultar a amamentação ou, simplesmente, facultar sua não realização" (MEYER, 2003, p. 48). Um dos desdobramentos relevantes desses discursos, para Meyer (2003), é a instauração de um processo de culpabilização das mulheres que não desejam e mesmo das que não podem ou são proibidas de amamentar, "pois elas aprendem - com o que não está dito que sua incapacidade ou condição interfere no 'desenvolvimento saudável' de seu filho" (MEYER, 2003, p. 48).

\section{Amamentação e divisão do corpo feminino: sexualidade e o tabu do seio} maternal

Sandre-Pereira (2003) traz uma rica comparação entre Brasil e França a respeito da temática da sexualidade da mulher durante o período da amamentação na perspectiva da antropologia social. Embora tenham uma história muito semelhante no que diz respeito à apropriação do tema pela medicina e pelo Estado, a autora salienta que os dois países vivem hoje realidades bastante distintas no que se refere às práticas e discursos sobre aleitamento materno. Apesar disso, ela aponta que, no caso da relação entre amamentação e sexualidade, foram as semelhanças entre os depoimentos dos dois grupos que chamaram sua atenção.

Uma das questões levantadas pelos pesquisados foi o dualismo entre seio maternal e seio erótico. Sandre-Pereira (2003) afirma que foram numerosos os entrevistados que confirmaram, nas suas vivências, uma espécie de proibição que o casal se impõe de tocar o seio materno durante o processo de amamentação, fenômeno que ela denominou 'tabu do seio materno' (SANDRE-PEREIRA, 2003, p. 479). Nas sociedades ocidentais contemporâneas, presenciaríamos uma forte sexualização do seio feminino, que é entendido como objeto de desejo e zona de prazer feminino durante a relação sexual, e esse imaginário acerca dessa parte do corpo da mulher seria inconciliável, em alguns casos, com a maternagem no que tange à amamentação. 
Outra questão importante apontada pelas mulheres foi a baixa da libido após o parto. Sobre esse ponto, a autora afirma que, embora ocorram mudanças hormonais no período apontadas pela literatura médica como possíveis inibidoras da libido, como a baixa do estrogênio e da progesterona e o aumento da prolactina, tais variações não devem ser entendidas como a única razão para as transformações no comportamento sexual dos entrevistados.

\begin{abstract}
Essas questões são certamente importantes e devem ser levadas em conta; contudo, elas não explicam a totalidade do fenômeno. (...) Segundo minhas informantes, o retorno a uma vida sexualmente ativa com o companheiro costuma ser alvo de negociações, nem sempre satisfatórias para ambas as partes. Nesse sentido, não são raros os relatos sobre a dedicação exclusiva da mãe ao bebê, colocando o companheiro em segundo plano, o que é sentido por muitos homens como uma rejeição. (SANDRE-PEREIRA, 2003, p. 477-478)
\end{abstract}

A discussão sobre os seios femininos e sua dupla relação com a amamentação e a sexualidade e individualidade feminina também está presente no trabalho de Monteiro, Gomes e Nakano (2006). As autoras propõem uma análise sob a ótica da sexualidade e dos direitos reprodutivos, mas sua apropriação não segue a mesma linha naturalista abordada anteriormente. Ao contrário, elas observam que os discursos em prol do aleitamento materno, utilizados para difundir a prática como comportamento social universal das mulheres, "tendem a evidenciar a visão romântica deste ato, omitindo possíveis problemas que possam ocorrer" (MONTEIRO; GOMES; NAKANO, 2006, p. 148), inclusive relacionados às diferentes significações do seio e do corpo feminino como um todo para a mulher e a sociedade.

Monteiro, Gomes e Nakano (2006) defendem, portanto, a formulação de um novo modelo de atenção, que supere o modelo ainda em vigor na atualidade e passe a respeitar o direito de as mulheres decidirem que utilização farão de seus seios e corpos. “Aos profissionais de saúde cabe o acolhimento a estas mulheres, a compreensão do seu modo de vida e o respeito às suas opiniões, para assim, apoiá-la nas decisões referentes ao processo de amamentação" (MONTEIRO; GOMES; NAKANO, 2006, p. 149).

O aleitamento materno se dá com base em uma íntima relação entre o corpo da mãe o do bebê. Corpos que são físicos, instintivos, repletos de sensações operadas 
fisiologicamente, mas que estão, paralelamente, submetidos a valores e controles culturalmente determinados. Como aponta Rodrigues (1983), o homem é uma matéria na qual "coexistem um corpo biológico e um corpo social” (RODRIGUES, 1983, p. 125). Nesse sentido, é interessante voltar-se para a abordagem de diversos autores da psicanálise sobre a amamentação, enfocando-o como o estabelecimento de uma relação erógena entre mãe e filho(a), relação a partir da qual a mãe adquire uma importância tão fundamental na vida da criança que acaba por se tornar, "para os dois sexos, o primeiro objeto e o protótipo de todas as relações amorosas ulteriores" (QUEIROZ, 2005, p. 76).

Segundo Queiroz (2005), alguns estudiosos ressaltam que essa relação instituída por meio do aleitamento é, para a mãe, uma experiência repleta de sensações sexuais, decorrentes, principalmente, do reflexo fisiológico gerado pela sucção do seio pelo bebê. No entanto, esse "alcance sexual" da amamentação estende-se para além do binômio mãe-filho, interferindo na interação da mulher com seu parceiro. Muitos autores destacam, por exemplo, como a dupla função dos seios femininos nas sociedades ocidentais contemporâneas - erótica e maternal - e a intensidade sexual do processo de amamentação provocam alterações na vida sexual do casal no período de aleitamento.

As reflexões propostas nesses artigos parecem indicar que o imenso investimento físico e emocional vivido pela mãe no cuidado com o filho após o parto, quando ela passa a "investir libidinalmente seu bebê" (CASTRO, 2006, p. 177), torna-se, algumas vezes, um empecilho ou elemento complicador do envolvimento sexual da mulher com o parceiro. A díade mãe-bebê, marcada pela indissociação dos corpos que se inicia durante gravidez e continua com a amamentação, certamente é um fator que limita o ingresso de um terceiro - em geral, o pai - nessa relação, influenciando, decisivamente, a retomada da vida sexual do casal após o parto.

\section{Considerações finais}

O aleitamento materno é hoje intensamente estimulado pelas organizações internacionais e por políticas públicas nacionais como estratégia de saúde pública que 
influencia, decisivamente, na redução das taxas de morbimortalidade infantil e no incremento da saúde da criança em várias partes do mundo. Junto a esse imperativo da amamentação vivido nas últimas décadas, vem, de acordo com vários autores, um modelo de maternidade caracterizado por uma responsabilização da mulher por todo e qualquer risco a que sua prole possa estar submetida e por uma necessidade cada vez maior de profissionais e conhecimentos especializados em ajudar as mães na criação e educação dos filhos. Segundo Wall (2001) e muitos outros autores, a amamentação, principalmente nas últimas décadas, transformou-se na “medida da mãe", determinando se sua conduta materna é ou não correta de acordo com os padrões socialmente valorizados.

Se, durante a forte empreitada da indústria alimentícia de produção de fórmulas infantis que teve lugar, desde as primeiras décadas do século XX (REA, 1990), em países da Europa e nos Estados Unidos, uma das apropriações é que o corpo da mulher foi gradativamente visto como desnecessário e mesmo incapaz de garantir a alimentação e a qualidade de vida do seu bebê, ao contrário, na era em que vivemos, o corpo da mulher torna-se, novamente, objeto de regulações, mas agora como instrumento necessário à garantia da saúde da criança por meio da adoção do aleitamento materno nos moldes apregoados pelos governos e organizações internacionais.

Em relação ao debate mundial envolvendo a amamentação, é interessante notar que, nos Estados Unidos, a recomendação adotada pela American Academy of Pediatrics (Academia Americana de Pediatria) é de que o aleitamento materno seja estendido até, pelo menos, 1 ano de idade da criança, e não os 2 anos ou mais preconizados pela OMS/Unicef e pelo Ministério da Saúde brasileiro. No entanto, é desse país que se origina grande parte dos trabalhos elencados neste artigo, em sua maioria reflexões que problematizam os discursos contemporâneos sobre maternidade e amamentação numa perspectiva de gênero.

Ao longo da pesquisa bibliográfica realizada para este trabalho, encontramos, inclusive, o artigo de Lee (2011), que foca sua análise na situação da Grã-Bretanha, país onde, a despeito das orientações oficiais sobre alimentação infantil, muitas mulheres alimentam seus bebês com fórmulas ainda nas primeiras semanas após o parto. Ela 
propõe uma revisão de pesquisas publicadas neste século "that engages critically with the mantra 'Breast is Best' and the associated expansion of official breast-feeding promotion programmes"9 (LEE, 2011, p. 1058), e, utilizando muitos dos referenciais que citamos ao longo deste texto, também aborda as principais apropriações de gênero sobre questões relativas à maternidade e a amamentação.

Embora, como explicitado na vertente mais naturalista apresentada neste trabalho, existam grupos feministas empenhados em estabelecer relações cada vez mais sólidas entre a amamentação e a saúde reprodutiva da mulher, entendendo-a como um direito e uma forma de afirmação por parte da mulher, da sua própria feminilidade perante a sociedade, a maioria dos artigos encontrados nesta revisão nos indicou um caminho mais crítico em relação, sobretudo, aos discursos oficiais e políticas públicas dirigidas a essa temática, geralmente associada à saúde da criança como foco principal.

Em nosso país, se consideramos a forte defesa governamental do aleitamento materno como política, que se estende por diversas estratégias, sobretudo no âmbito da atenção materno-infantil, presenciamos um debate público quase inexistente, a despeito da crescente contribuição dada por autoras e autores do campo da saúde, das ciências sociais e dos estudos de gênero. Esperamos que o breve panorama que oferecemos neste artigo possa ser útil, dando maior visibilidade aos trabalhos desenvolvidos, tanto no Brasil quanto em outros países, e fomentando uma discussão mais plural a respeito da amamentação e de suas implicações para a mulher, abrangendo questões como saúde, subjetividade, trabalho, sexualidade e seus múltiplos papéis na sociedade contemporânea.

\section{Referências Bibliográficas}

AMORIM, Suely Teresinha. Schmidt Passos de. Aleitamento materno ou artificial: práticas ao sabor do contexto. Brasil (1960-1988). Estudos Feministas. Florianópolis: UFSC, v. 16, n. 2, p. 581-598, maio-ago 2008. Disponível em: <http://www.scielo.br/pdf/ref/v16n2/14.pdf>. Acesso em: 21 out. 2012.

\footnotetext{
${ }^{9}$ [Este artigo revê a pesquisa publicada neste século] que se engaja criticamente em relação ao mantra 'O peito é melhor' e à associada expansão de programas oficiais de promoção da amamentação. (TN)
} 
BADINTER, Elisabeth. O conflito: a mulher e a mãe. Tradução V. L. dos Reis. Rio de Janeiro: Record, 2011.

BADINTER, Elisabeth . Um amor conquistado: o mito do amor materno. Rio de Janeiro: Nova Fronteira, 1985.

BRASILEIRO, Aline Alves et al. A amamentação entre filhos de mulheres trabalhadoras. Rev Saúde Pública. São Paulo: USP, v. 46, n. 4, p. 642-648, 2012. Disponível em: < http://www.revistas.usp.br/rsp/article/view/48333/52192>. Acesso em: 11 jan. 2013.

CASTRO, Marcelo José de A mulher com dificuldades para amamentar: algumas considerações psicanalíticas. In: CASTRO,Lilian Mara Consolin Poli de.; ARAÚJO, Lylian Dalete Soares de. (Org.) Aleitamento materno: manual prático. 2. ed. Londrina: 2006. p. 173-181.

CORRÊA, Sonia. O conceito de gênero: teorias, legitimação e usos. In: BARSTED, Leila Linhares; PITANGUY, Jaqueline. (Org.) O Progresso das mulheres no Brasil 2003-2010. Rio de Janeiro: Cepia; Brasília: ONU Mulheres, p. 339-344, 2011. Disponível em: <http://www.unifem.org.br/sites/700/710/progresso.pdf>. Acesso em: 11 jun. 2013.

COSTA, Jurandir Freire. Ordem médica e norma familiar. 4. ed. Rio de Janeiro: Graal, 1999.

FEIN, Sara B.; ROE, Brian. The effect of work status on initiation and duration of breastfeeding. American Journal of Public Health, v. 88, n. 7, p. 1042-1046, 1998. Disponível em: <http://www.ncbi.nlm.nih.gov/pmc/articles/PMC1508266/pdf/amjpho0019-0040.pdf>. Acesso em: 9 out. 2012.

HAUSMAN, Bernice L. Women's liberation and the rhetoric of "choice" in infant feeding. International Breastfeeding Journal, v. 3, n. 10, 2008. 3 p. Disponível em: <http://www.internationalbreastfeedingjournal.com/content/pdf/1746-4358-3-10.pdf >. Acesso em: 24 dez. 2011.

HAYS, Sharon. Contradições culturais da maternidade. Rio de Janeiro: Gryphus, 1998.

KNAAK, Stephanie J. The roblem with breastfeeding discourse. Canadian Journal of Public Health, v. 97, n. 5, p. 412-414, sep-oct., 2006. Disponível em:

<http://journal.cpha.ca/index.php/cjph/article/view/700/700>. Acesso em: 09 mar. 2013.

KUKLA, Rebecca. Ethics and Ideology in Breastfeeding Advocacy Campaigns. Hypatia, v. 21, n. 1, p. 157-180, win 2006. Disponível em:

<http://onlinelibrary.wiley.com/doi/10.1111/j.1527-2001.2006.tboo970.x/pdf>. Acesso em: 11 jun. 2013. 
LABBOK, Miriam H.; SMITH, Paige Hall.; TAYLOR, Emily C. Breastfeeding and feminism: a focus on reproductive health, rights and justice. International Breastfeeding Journal, v. 3, n. 8, 2008. 6p. Disponível em: <http://www.internationalbreastfeedingjournal.com/content/pdf/1746-4358-3-8.pdf>. Acesso em: 29 mai. 2013.

LEE, Ellie. Breast-Feeding Advocacy, Risk Society and Health Moralism: A Decade's Scholarship. Sociology Compass, v. 5, n. 12, p. 1058-1069, 2011. Disponível em: <http://onlinelibrary.wiley.com/doi/10.1111/j.1751-9020.2011.00424.x/full>. Acesso em: 3 jan. 2013.

MEYER, Dagmar Estermann. Teorias e políticas de gênero: fragmentos históricos e desafios atuais. Rev Bras . Enferm. Brasília, v. 57, n. 1, p. 13-18, jan-fev 2004. Disponível em: <http://www.scielo.br/pdf/reben/v57n1/a03v57n1.pdf>. Acesso em: 24 jul. 2013.

MEYER, Dagmar Estermann . Educação, saúde e modos de inscrever uma forma de maternidade nos corpos femininos. Movimento. Porto Alegre, v. 9, n. 3, p. 33-58, set-dez 2003. Disponível em: < http://www.redalyc.org/articulo.oa?id=115317979003>. Acesso em: 13 abr. 2013.

MONTEIRO, Juliana Cristina dos Santos.; GOMES, Flávia Azevedo.; NAKANO, Ana Maria Spanó. Amamentação e o seio feminino: uma análise sob a ótica da sexualidade e dos direitos reprodutivos. Texto Contexto Enferm, Florianópolis, v. 15, n. 1, p. 146-150, 2006. Disponível em: <http://www.scielo.br/pdf/tce/v15n1/a18v15n1.pdf>. Acesso em: 07 mar. 2012.

O'CONNOR, Richard A.; VAN ESTERIK, Penny. Breastfeeding as custom not culture:utting meaning down to size. Anthropology Today vol. 28, n. 5, p. 13-16, oct 2012. Disponível em: <http://onlinelibrary.wiley.com/doi/10.1111/j.1467-8322.2012.00897.x/pdf>. Acesso em: 08 abr. 2013.

PERROT, Michelle. Os silêncios do corpo da mulher. In: MATOS, Maria Izilda S. de; SOIHET, Rachel. (Org.). O corpo feminino em debate. São Paulo: Editora Unesp, 2003. p. 13-27.

QUEIROZ, Telma Corrêa da Nóbrega. Do desmame ao sujeito. São Paulo: Casa do Psicólogo, 2005.

REA, Marina Ferreira. Substitutos do leite materno: passado e presente. Rev. Saúde Púb., S. Paulo, v. 24, p. 241-249, 1990. Disponível em: <http://www.scielo.br/pdf/rsp/v24n3/11.pdf>. Acesso em: 02 jul. 2013.

RIPPEYOUNG, Phyllis L. F.; NOONAN, Mary C. Is breastfeeding truly free? The economic consequences of breastfeeding for women. In: 2009 ANNUAL MEETING OF POPULATION ASSOCIATION OF AMERICA. Detroit: Princeton, 2009, 23 p. Disponível em: 
<http://paa2009.princeton.edu/papers/91391>. Acesso: 13 ago. 2012. RODRIGUES, José Carlos. Tabu do corpo. 3. ed. Rio de Janeiro: Achiamé, 1983.

SANDRE-PEREIRA, Gilza. Amamentação e sexualidade. Estudos Feministas, Florianópolis, v. 11, n. 2, p. 467-491, jul-dez 2003. Disponível em:

<http://www.periodicos.ufsc.br/index.php/ref/article/view/9842/9071>. Acesso em: 24 mai. 2013.

SCAVONE, Ucila. Dar a vida e cuidar da vida: feminismo e ciências sociais. São Paulo: Editora Unesp, 2004.

SMITH, Paige Hall. Is it just so my right? women repossessing breastfeeding. International Breastfeeding Journal, v. 3, n. 12, 2008. 6p. Disponível em:

<http://www.internationalbreastfeedingjournal.com/content/pdf/1746-4358-3-12.pdf >. Acesso em: 13 dez. 2012.

TAYLOR, Erin N.; WALLACE, Lora Ebert. For shame: feminism, breastfeeding advocacy, and maternal guilt. Hypatia, v. 27, n. 1, p. 76-98, win 2012. Disponível em:

<http://onlinelibrary.wiley.com/doi/10.1111/j.1527-2001.2011.01238.x/pdf>. Acesso em: 23 nov. 2012.

WALL, Glenda. Moral constructions of motherhood in breastfeeding discourse. Gender \& Society, v. 15, n. 4, p. 592-610, aug 2001. Disponível em:

<http://gas.sagepub.com/content/15/4/592>. Acesso em: 25 nov. 2011.

WOLF, Joan B. Is breast really best? Risk and total motherhood in the National Breastfeeding Awareness Campaign. J Health Polit Policy Law, v. 32, n. 4, p. 595-636, 2007. Disponível em: <http://jhppl.dukejournals.org/content/32/4/595.full.pdf>. Acesso em: 02 set. 2011.

WOLF, Jacqueline H. Got milk? Not in public! International Breastfeeding Journal, v. 3, n. 11, 2008. 3 p. Disponível em:

<http://www.internationalbreastfeedingjournal.com/content/pdf/1746-4358-3-11.pdf>. Acesso em: 23 jun. 2013. 
